\title{
Eskişehir Lületaşı Atıklarından Sütunlanmış Kil Üretimi ve Karakterizasyonu
}

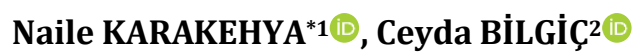 \\ ${ }^{1}$ Eskişehir Osmangazi Üniversitesi, Eskişehir Meslek Yüksekokulu, Çevre Koruma ve Kontrol Programı, 26480, \\ Eskişehir, Türkiye \\ 2 Eskișehir Osmangazi Üniversitesi, Mühendislik Mimarlık Fakültesi, Kimya Mühendisliği Bölümü, 26480, \\ Eskişehir, Türkiye
}

(Alınış / Received: 09.02.2020, Kabul / Accepted: 14.07.2020, Online Yayınlanma / Published Online: 20.08.2020)

\author{
Anahtar Kelimeler \\ Sepiyolit, \\ Montmorillonit, \\ Sütunlanmış-kil, \\ Ters gaz kromatografisi, \\ Atık değerlendirme
}

\begin{abstract}
Özet: Kil mineralleri, pek çok endüstriyel uygulamada çok eski çağlardan beri kullanılan doğal nano-maddelerdir. Bu mineralleri, adsorban veya katalizör olarak daha kullanışlı hale getirmek için uygulanan işlemlerden biri de hidroksi metal katyonlar ile sütunlamadır. Bu işlem ile tabakalı yapıların gözenek boyutu değiştirilebilir. Bu çalışmada iki tür sütunlanmış kil incelenmiştir. Birincisi, Eskişehir lületaşı tesisi atıklarından alfa-sepiyolit kullanılarak üretilen Alsütunlanmış sepiyolittir. Diğer sütunlanmış kil (Al-sütunlanmış montmorillonit) ise ticari bir üründür. Al-sütunlanmış sepiyolit ve Al-sütunlanmış montmorillonitin bir lineer alkan serisi ile bazı yüzey etkileşimlerini değerlendirmek için sonsuz seyrelme koşullarında ters gaz kromatografisi (TGK) uygulanmıştır. Sütunlanmış killerin çeşitli fiziksel ve kimyasal özellikleri taramalı elektron mikroskopisi (SEM), X-ışını kırınım (XRD) metodu ve Fourier Dönüşümlü Kızılötesi (FT-IR) spektroskopisi yardımıyla değerlendirilmiştir.
\end{abstract}

\section{Preparation and Characterization of Pillared Clay from Eskişehir Meerschaum Wastes}

\section{Keywords}

Sepiolite,

Montmorillonite,

Pillared-clay,

Inverse gas chromatography,

Waste utilization

\begin{abstract}
Clay minerals are natural nano-materials that have been used in many industrial applications since ancient times. One of the processes applied to make these minerals more useful as adsorbent or catalyst, is pillaring with hydroxy metal cations. Through this process, the pore size of the layered structures can be changed. In this study, two kinds of pillared clays were examined. The first one was Al-pillared sepiolite produced using alpha-sepiolite from Eskişehir meerschaum facility wastes. The other pillared clay (Al-pillared montmorillonite) was a commercial product. Inverse gas chromatography (IGC) at infinite dilution conditions was applied to evaluate the some surface interactions of Al-pillared sepiolite and Al-pillared montmorillonite with a series of linear alkane. Various physical and chemical properties of the pillared-clays have been evaluated with the aid of scanning electron microscopy (SEM), X-ray diffraction (XRD) method and Fourier Transform Infrared (FT-IR) spectroscopy.
\end{abstract}

\section{Giriş}

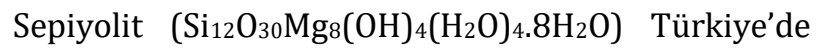
bol miktarda bulunan fillosilikat türü kil minerallerinin bir üyesidir [1]. Adsorpsiyon kapasitesi yüksek olduğundan hem akademik çalışmalarda hem de endüstriyel uygulamalarda ilgi çekmektedir. Sepiyolit, alfa-sepiyolit (lifli tip) ve betasepiyolit (laminar tip) olarak ikiye ayrllır. Alfasepiyolit Almanca'da "meerschaum", Osmanlı Türkçesinde "derya köpüğ̈̈" olarak bilinir [2]. Sepiyolit, Somali, Çekya, ABD, Yunanistan, İspanya, Çin ve Fransa gibi ülkelerde bulunur [2]. Ancak en kaliteli alfa-sepiyolit yani lületaşı Eskişehir'de bulunmaktadır [3]. Ayrıca dünya sepiyolit rezervinin büyük bir kısmı Türkiye'de bulunmaktadır [4]. Eskişehir'de lületaşı, pipo, süs eşyaları ve diğer eşyaların yapımında kullanılır. Lületaşı'nın \%30\%40'ı işleme sırasında atığa dönüşür [3]. Bu atık oranı oldukça yüksektir. Ayrıca lületaşı gibi çok az ülkede bulunan bir doğal hammadde sadece süs eşyası üretiminde değil, katma değeri yüksek uç ürünlerin elde edilmesinde de kullanılmalıdır.

Son yıllarda, çeşitli katılarda gözenek oluşturma, gözenek miktarını ve boyutunu kontrol etmeye 
yönelik işlemlere sokma, doğadaki gözenekli maddelerin benzerini üretme gibi işlemler oldukça ilgi görmektedir. Sütunlama da bir çeşit gözenek oluşturma çalışmasıdır. Uluslararası Temel ve Uygulamalı Kimya Birliği (IUPAC), bu işlemi şöyle tanımlar: "Sütunlama, katmanlı bir bileşiğin, tabaka yapısı korunarak ısıl olarak kararlı mikro ve/veya mezo-gözenekli bir malzemeye dönüştürüldüğü bir işlemdir" [5]. Eğer bu işlemde kullanılan katı kil minerali ise elde edilen ürüne sütunlanmış kil denir. Sütunlanmış killer, sütun tipine göre geniş yüzey alanı ve büyük gözenek hacimlerinin elde edilebildiği yeni bir malzeme sınıfıdır [6]. Bu katılar, adsorpsiyon uygulamaları ve katalitik süreçler için oldukça önemli bir potansiyele sahiptir [7]. Sütunlama işlemi, açılabilen kil tabaklarının arasındaki küçük katyonların $\left(\mathrm{Na}^{+}\right.$ve $\mathrm{Ca}^{2+}$ gibi), büyük inorganik polikatyonlarla yer değiştirmesi sağlanarak yapılır. Daha sonra isitma işlemiyle (kalsinasyon) gerçekleşen dehidrasyon ve dehidroksilasyonla polikatyonlar, ısıya dayanıklı ve sağlam metal sütunlara dönüştürülürler. Böylece kil tabakalarının arasındaki mesafe genişletilmiş olur. Günümüzde en çok kullanılan sütunlama ajanlarından biri $\mathrm{Al}_{13}$ polioksokatyonudur (Keggin molekülü olarak bilinir, $\left.\left[\mathrm{AlO}_{4} \mathrm{Al}_{12}(\mathrm{OH})_{24}\left(\mathrm{H}_{2} \mathrm{O}\right)_{12}\right]\right)[8,9]$.

Yirmi yılı aşkın bir süredir kullanılan ters gaz kromatografisi (inverse gas chromatography, IGC) geleneksel gaz kromatografisinin bir türevidir, ancak yaygın kullanılan kromatografinin aksine, incelenen malzeme gaz kromatografi kolonundaki sabit fazdadır. Mobil fazın (prob) tutulma hacmi, prob ile kolondaki malzemenin yüzeyi arasındaki etkileşimi gösterir [10,11]. TGK, pürüzlü ve gözenekli tozların yüzey enerjisini ölçmek için mükemmel bir yöntem sağlar [12]. Yüzey enerjisi, katının yüzeyindeki dengelenmeyen moleküler kuvvetlerin sonucudur. Serbest yüzey enerjisinin iki bileşeni olduğu düşünülebilir: dağılım ve spesifik [13]. Bir dizi homolog n-alkanın tutulma süresi, sütunlu killerin dağılım yüzey enerjisini $\left(\gamma_{s^{d}}\right)^{2}$ belirlemek için kullanılır. TGK çalışmalarında $\gamma_{S^{\mathrm{d}}}$ değeri yaygın olarak Schultz ve Lavielle tarafindan verilen aşağıdaki Eşitlik 1'den belirlenir [10]:

$$
\operatorname{RTIn}\left(V_{N}\right)=2 N a\left(\gamma_{S}^{d}\right)^{1 / 2}\left(\gamma_{L}^{d}\right)^{1 / 2}+C
$$

Burada, R, ideal gaz sabiti, T, mutlak kolon sıcaklığ (K), A, adsorbatın (bu çalışmada alkan serisi) kapladığı moleküler yüzey alanı, N, Avogadro sayısı, $\gamma_{\mathrm{L}}^{\mathrm{d}}$, adsorbatın yüzey serbest enerjisi, C, seçilen standart duruma bağlı olan bir sabit ve $V_{N}$ ise adsorbatın net alıkonma hacmidir. $\mathrm{V}_{\mathrm{N}}$ için hesaplama yöntemi daha önceki çalışmamızda verilmiştir [14]. Net alıkonma süresi pik maksimumlarından hesaplanmiştır.

Adsorpsiyonun standart entalpi değişimi $(\Delta \mathrm{H})$ ve standart serbest enerji değişimi $(\Delta G)$, alıkonma hacminin sıcaklığa bağlılığından türetilmiştir $[15,16]$.
$\Delta \mathrm{H}$ ve $\Delta \mathrm{G}$ değerleri sırasıyla Eşitlik 2 ve Eşitlik 3 yardımıyla hesaplanmıştır:

$$
\begin{gathered}
\Delta H=-R \frac{d \operatorname{In}\left(V_{N}\right)}{d(1 / T)} \\
\Delta G=-R T \operatorname{In}\left(\frac{V_{N} P_{0}}{m S \pi_{0}}\right)
\end{gathered}
$$

Burada, m, sabit fazın ağırlığı, S, toplam yüzey alanı, $\mathrm{P}_{0}$, adsorbatın buhar basıncidır ve 1 atm olarak alınmıştır, $\pi_{0}$, iki boyutlu referans yüzeyin basıncıdır ve 3,38.10-4 $\mathrm{Nm}^{-1}$ kabul edilmiştir [17]. Adsorpsiyon standart entalpi değişimi $(\Delta S)$, Eşitlik 4 kullanılarak hesaplanmiștır:

$$
\Delta S=\frac{(\Delta H-\Delta G)}{T}
$$

$\mathrm{Bu}$ çalışmada, atık lületaşından birçok alanda kullanılan bir ürün (adsorban, katalizör) olan Alsütunlanmış sepiyolit üretilmiştir. Al-sütunlanmış sepiyolitin çeşitli fizkokimyasal parametreleri ters gaz kromatografisi yardımıyla belirlenerek ticari bir ürün olan Al-sütunlanmış montmorillonit ile karşılaștırılmıştır. Ayrıca SEM, XRD ve FT-IR yöntemleri kullanılarak incelenen maddelerin yapısal özellikleri karşılaştırılmış ve yorumlanmıştır.

\section{Materyal ve Metot}

\subsection{Materyal}

Al-sütunlanmış montmorillonit Sigma-Aldrich firmasından temin edilmiştir. Alfa-sepiyolit, Sivrihisar/Eskişehir bölgesinden (Türkiye) alınmış ve Al-sütunlanmış sepiyolit üretiminde kullanılmıştır. Sepiyolit, bazı safsızlıklar içerdiğinden bir dizi saflaştırma işlemi uygulanmıştır. Sepiyolit bol miktarda saf su ile karıştırılmış ve çökmeye bırakılmıştır. Bir gün bekletildikten sonra dipteki tortu uzaklaştırılmıştır. Aynı işleme safsızlık kalmayıncaya ve tanecik boyutu $2 \mu$ m'nin altındaki kısım elde edilinceye kadar devam edilmiştir [18]. Elde edilen saf sepiyolit etüvde kurutulmuş ve ögütülmüştür. $\mathrm{Bu}$ çalışmada, incelen maddelerin tanecik boyut aralı̆̆ 150-300 $\mu$ m'dir.

\subsection{Sütunlama işlemi}

Sütunlama işlemi için ilk olarak $400 \mathrm{ml}$ ve $0,1 \mathrm{M}$ $\mathrm{NaOH}$ çözeltisi çok yavaş bir şekilde damla damla (dakikada yaklaşık 30 damla hızında), $200 \mathrm{ml}$ ve 0,1 $\mathrm{M} \mathrm{AlCl} 3$ çözeltisine eklenmiştir. Damlatma işlemi bittikten sonra çözelti 2 saat $60{ }^{\circ} \mathrm{C}$ 'de isitıcılı manyetik karıştırıcıda karıştırılmıştır. Daha sonra 12 saat oda sıcaklığında bekletilmiştir. Bu sütunlama çözeltisinden $500 \mathrm{ml}$ alınarak içine 10 gram sepiyolit (suda çözünmüş halde) eklenmiştir. Karışım 2 saat 60 ${ }^{\circ} C^{\prime}$ de ısıtıcılı manyetik karıştırıcıda karıștırılmıştır. 
Sonrasında santrifüjle katı madde çözeltiden alınarak defalarca distile su ile yıkanmiștır. Elde edilen sütunlanmış kil etüvde kurutulduktan sonra 400 ${ }^{\circ} \mathrm{C}$ 'de 2 saat kalsine edilmiştir.

\subsection{Karakterizasyon}

İnce toz haline getirilmiş sütunlu killerin X-ışını kırınımı (XRD) modelleri, $40 \mathrm{kV} / 30 \mathrm{~mA} \quad \mathrm{CuK} \alpha$ radyasyonunda Rigaku Ultima-IV difraktometresi kullanılarak $2^{\circ} \mathrm{dk}^{-1}$ tarama hızında ve $1^{\circ}-12^{\circ}(2 \theta)$ aralığında kaydedilmiştir. Sütunlanmış killerin soğurma kızılötesi spektrumları bir Perkin Elmer 100 FT-IR spektrometresi kullanılarak elde edilmiştir. Numunelerin mikroskobik görüntüleri JEOL 5600 LV taramalı elektron mikroskobu kullanılarak çekilmiştir. Görüntülemeden önce numunelere altın kaplama işlemi yapılmıştır.

Ters gaz kromatografisi analizleri Agilent 7890 kromatografi cihazı kullanılarak 300, 310, 320 ve 330 ${ }^{\circ} \mathrm{C}$ kolon sıcaklıklarında yapılmıştır. Kolon giriş sıcaklığı $250{ }^{\circ} \mathrm{C}$ ve detektör sıcaklığı $350{ }^{\circ} \mathrm{C}$ olarak ayarlanmıştır. Kolonda sürükleyici gaz olarak $40 \mathrm{ml}$ $\mathrm{dk}^{-1}$ akış hızında yüksek saflıkta $\mathrm{N}_{2}$ kullanılmıştır. Paslanmaz çelik gaz kromatografisi kolonuna 2 gram numune konularak bir kompresör yardımıyla iki ucu cam yünü ile kapatılmıştır. Adsorbat olarak bir alkan serisi (analitik saflıkta hekzan, heptan, oktan ve nonan) kullanılmıştır ve sonsuz seyrelme yani sıfır yüzey kaplanması koşullarında çalışılmıştır. Alıkonulmadan (adsorpsiyon - desorpsiyon olmadan) kolonu geçme süresi metan yardımıyla belirlenmiştir. Analizlere başlanmadan önce kolon 2 saat $330{ }^{\circ} \mathrm{C}$ 'de şartlanmıştır. Ters gaz kromatografisi analizlerinde, piklerin simetrik olmasına ve pik maksimum noktasının alkan enjeksiyon hacminden bağımsız olmasına dikkat edilmiştir. Böylece sonsuz seyrelme bölgesinde ve alkan moleküllerinin sadece incelenen katı yüzeyi ile etkileşiminin dikkate alındığı dolayısıyla kendi aralarındaki etkileşimlerin ihmal edilebildiği çalışma koşulu sağlanmıştır. Net alıkonma süreleri pik maksimumlarından belirlenmiștir. Her analiz en az üç kez tekrarlanmış ve ortalaması alınmıştır.

\section{Bulgular}

Al-sütunlanmış sepiyolit ve Al-sütunlanmış montmorillonitin düşük $2 \theta$ bölgesindeki XRD desenleri Şekil l'de gösterilmiştir.

Al-sütunlanmış sepiyolit, 7,2 ${ }^{\circ}$ de $(2 \theta)$ bazal mesafesi $12,33 \AA$ Å olan ve (110) düzlemine karşılık gelen yoğun bir yansıma göstermiştir. Önceki çalışmalar incelendiğinde, sepiyolitin (110) düzlemindeki bazal mesafesinin 12,3 ̊ olarak bulunduğu görülmüștür [19]. Bu nedenle, sütunlaşma sonrasında, sepiyolitin temel yapısının ve kristal özelliğinin korunduğu söylenebilir. Al-sütunlanmış montmorillonitin bazal mesafesinin değeri $4,9^{\circ}$ de (20) 18,07 Å'dur.
Termodinamiksel parametrelerin belirlenmesi için katının yüzey alanının kesinlikle bilinmesi gerekir. Daha önceki çalışmamızda, Al-sütunlanmış sepiyolit ve Al-sütunlanmış montmorillonitin BET tek noktalı yüzey alanı sırasıyla $288 \mathrm{~m}^{2} \mathrm{~g}^{-1}$ ve $211 \mathrm{~m}^{2} \mathrm{~g}-1$ olarak belirlenmiştir [20]. Ham sepiyolitin yüzey alanı da, genellikle ham montmorillonitin yüzey alanından daha yüksektir.

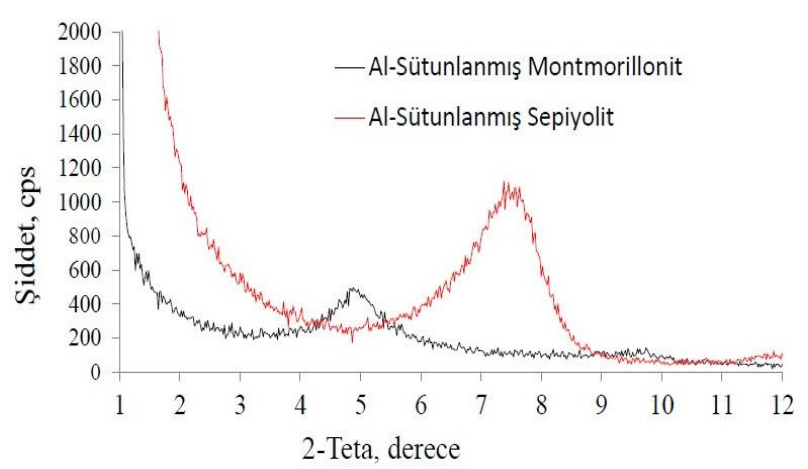

Şekil 1. Al-sütunlanmış montmorillonit ve Al-sütunlanmıș sepiyolit için XRD kırınım desenleri Şekilde sunulan bilginin açıklaması [2].

Ham sepiyolit ve Al-sütunlanmış sepiyolitin 400$3500 \mathrm{~cm}^{-1}$ dalga sayısı aralığında FT-IR spektrumları Şekil 2'de verilmektedir. Ham sepiyolit spektrumunda $1490 \mathrm{~cm}^{-1}$ de görülen ama Alsütunlanmış sepiyolitte bulunmayan bant dolomitten oluşan safsızlıktan kaynaklanmaktadır [21]. Ayrıca, Al-sütunlanmış sepiyolitin spektrumunda, $3300 \mathrm{~cm}^{-}$ ${ }^{1}$ 'deki bandın yayvanlaşması Keggin iyonlarının varlığına bağlanabilir [22]. Geri kalan pikler ise (440 $\mathrm{cm}^{-1}, 670 \mathrm{~cm}^{-1}, 1030 \mathrm{~cm}^{-1}, 1080 \mathrm{~cm}^{-1}$ ve $1210 \mathrm{~cm}^{-1}$ ) sepiyolitin FTIR spektrumunda gözlenen karakteristik piklerdir.

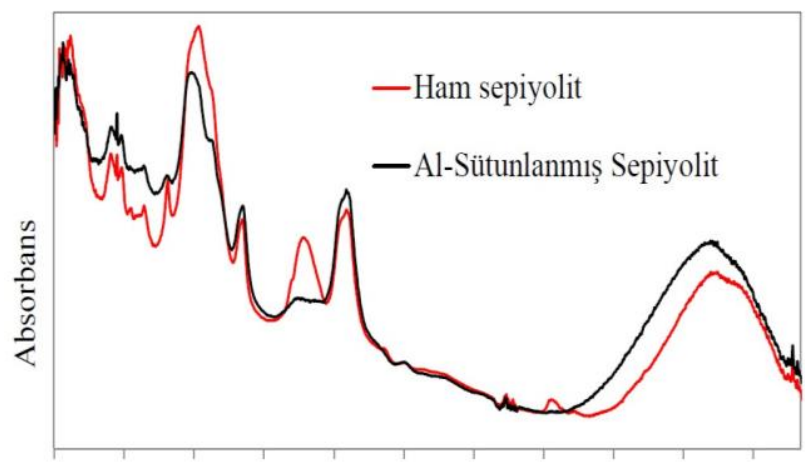

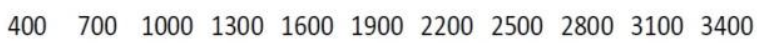

Dalga sayisı, $\mathrm{cm}^{-1}$

Şekil 2. Ham sepiyolit ve Al-sütunlanmış sepiyolit için FTIR spektrumları.

Tabakalı kil yapısına sahip olan Al-sütunlanmış sepiyolit ve Al-sütunlanmış montmorillonitin yüzey morfolojileri SEM ile gözlenmiştir ve her madde için 1000 ve 5000 büyütme oranında Şekil 3'de verilmiştir.

Sepiyolit, oluşma koşulları ve bulunduğu coğrafyanın sonucu olarak farklı kristal kusurlara, safsızlıklara, 
değişken büyüklüğe ve farklı topaklanma şekillerine sahip olabilir [21]. Aynı durum montmorillonit için de geçerlidir. Şekil 2'de görülebileceği gibi, Alsütunlanmış sepiyolit paralel ve yassı lif demetlerinin oluşturduğu birbirine bağlı düzlemsel yapılar (plakalar) sergilemektedir [19]. Plakaların uçlarındaki saçaklar rahatlıkla görülebilir. Sepiyolit için benzer görüntüler diğer çalışmalarda da bulunabilir [23,24].

TGK ile $\gamma_{S^{d}}$ değeri, çizilen RTIn $V_{N}-a\left(\gamma_{L}{ }^{d}\right)^{1 / 2}$ grafiğinin eğiminden hesaplanır (Eşitlik 1). Deneysel verilerin eşitliğe uygunluğunu ölçmek için çizilen grafiğin doğrusallığına bakılır. $\mathrm{Bu}$ çalışmada çizilen tüm grafiklerde belirleme katsayısının $\left(R^{2}\right)$ değeri 0,999'dan yüksektir. Al-sütunlanmış montmorillonit ve Al-sütunlanmış sepiyolit için kolon çalışma sıcaklıklarında hesaplanan $\gamma_{s}$ d değerleri Tablo 1'de verilmiştir. Her iki maddenin de serbest yüzey enerjisi sıcaklık artışıyla birlikte azalmaktadır. Alsütunlanmış sepiyolit için $\gamma_{s^{d}}$ değeri $63 \mathrm{~mJ} / \mathrm{m}^{2}(300$ ${ }^{\circ} \mathrm{C}$ ) ile $54 \mathrm{~mJ} / \mathrm{m}^{2}\left(330{ }^{\circ} \mathrm{C}\right)$ arasında değişirken, bu değer Al-sütunlanmış montmorillonit için daha yüksektir, $73 \mathrm{~mJ} / \mathrm{m}^{2}\left(300{ }^{\circ} \mathrm{C}\right)$ ile $70 \mathrm{~mJ} / \mathrm{m}^{2}\left(330^{\circ} \mathrm{C}\right)$ arasındadır.

İncelenen her iki maddenin de yüzey enerjisi sıcaklık artışı ile azalmaktadır. Sıcaklık artışıyla kohezyon kuvvetlerinin azaldığı düşünülürse bu beklenilen bir durumdur. Ancak görüldüğü üzere Al-sütunlanmış montmorillonitin serbest yüzey enerjisi sıcaklıkla çok az değișmektedir. Al-sütünlanmış sepiyolitte ise serbest yüzey enerjisi sıcaklıkla çok daha fazla değişmektedir. $\mathrm{Bu}$ da alkanların yüzey adsorpsiyonunun yanısıra sepiyolit liflerinin arasına girdiğinin göstergesi olabilir [25]. Bildiğimiz kadarıyla, Al-sütunlanmış sepiyolit için $\gamma_{S^{d}}$ değeri daha önceki çalışmalarda verilmemiștir. Ancak saf sepiyolit için yapılan birçok TGK çalışması mevcuttur. Aşkın ve Yazıcı [26], Sivrihisar sepiyolitinin $\gamma_{s^{d}}$ değerini $320{ }^{\circ} \mathrm{C}^{\prime} \mathrm{de} 84 \mathrm{~mJ} / \mathrm{m}^{2}$ ve $330{ }^{\circ} \mathrm{C}^{\prime}$ de $80 \mathrm{~mJ} / \mathrm{m}^{2}$ olarak hesaplamışlardır. $\mathrm{Bu}$ sonuçlara bakarak sütunlama işlemi neticesinde sepiyolitin yüzey enerjisinin düştügünü söyleyebiliriz. Lazarević ve arkadaşları [16], sepiyolitin $\gamma_{S}{ }^{\mathrm{d}}$ değerini $220{ }^{\circ} \mathrm{C}$ 'de $144 \mathrm{~mJ} / \mathrm{m}^{2}$ olarak hesaplamışlardır. Bandosz ve arkadașları [27], Al-sütunlanmış simektitin $\gamma_{\mathrm{s}}{ }^{\mathrm{d}}$ değerini $\quad 150 \quad{ }^{\circ} \mathrm{C}^{\prime}$ de $153 \mathrm{~mJ} / \mathrm{m}^{2}$ olarak hesaplamışlardır.

Tablo 1. İncelenen maddeler için $\gamma_{S^{\mathrm{d}}}$ değerleri.

\begin{tabular}{ccc}
\hline Sıcaklık $\left({ }^{\circ} \mathrm{C}\right)$ & $\begin{array}{c}\gamma \mathrm{s}^{\mathrm{d}}, \mathrm{Al}- \\
\text { sütunlanmış } \\
\text { montmorillonit }\end{array}$ & $\begin{array}{c}\gamma \mathrm{s}^{\mathrm{d}}, \mathrm{Al}- \\
\text { sütunlanmış } \\
\text { sepiyolit }\end{array}$ \\
\hline 300 & 73,0 & 62,8 \\
310 & 71,8 & 59,4 \\
320 & 70,7 & 57,2 \\
330 & 69,9 & 54,3 \\
\hline
\end{tabular}

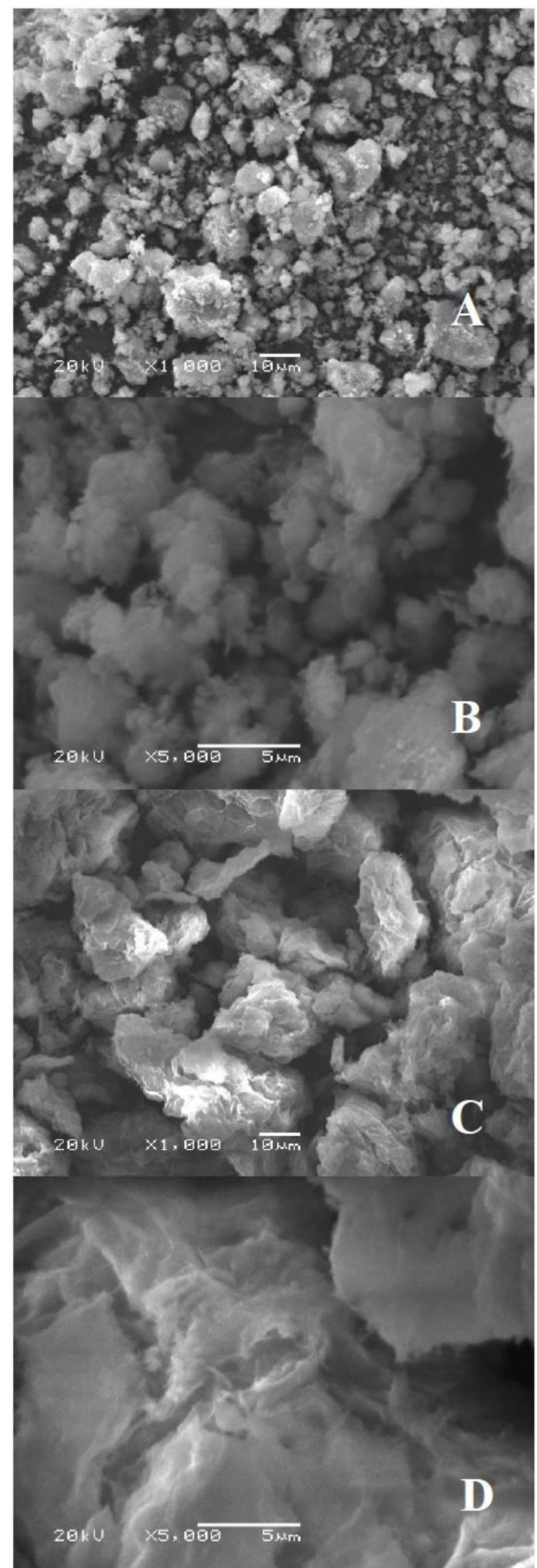

Şekil 3. Al-sütunlanmıș montmorillonit $(\mathrm{A}, \mathrm{B})$ ve $\mathrm{Al}-$ sütunlanmış sepiyolit için FT-IR spektrumları (C, D). 
Alkanlar, petrolün temel bileşenleridir. $\mathrm{Bu}$ nedenle alkan adsorpsiyonu, endüstride gaz akımlarının işlenmesi, hava kirliliği açısından uçucu organik bileşiklerin uzaklaştırılması ve iç ortam havasının temizlenmesi ve yakıt teknolojisi açısından doğal gaz depolanması gibi birçok sürece konu olmaktadır. Alsütunlanmış sepiyolit ve Al-sütunlanmış montmorillonit için her bir kolon çalışma sıcaklığında hesaplanan alkan serisi (C6-C9) adsorpsiyon termodinamik parametrelerinin ortalamaları sırasıyla Tablo 2 ve Tablo 3'de verilmiştir. İncelenen her iki madde içinde $\Delta \mathrm{H}$ ve $\Delta \mathrm{G}$ değerleri hep negatiftir bu da sırasıyla adsorpsiyonun ekzotermik olduğunu ve kendiliğinden gerçekleștiğini gösterir. $\Delta$ S'nin negatif olması sütunlanmış kil yüzeyinde adsorplanan derişiminin arttığını gösterir. Bu azalışın nedeni adsorplanan maddenin gaz haldekine göre daha düzenli bir hale geçmesi ve kargaşanın veya rastlantısallığın azalmasıdır [28]. Alkan serisinde zincir uzunluğu arttıkça alıkonma süresi uzamaktadır. Bu da alkanın karbon sayısı arttıkça $\Delta \mathrm{S}$ değerindeki düşüşün nedeni olabilir. Benzer sonuçlara Aşkın ve Yazıcı [26] tarafından da ulaşılmıştır.

Tablo 2. Al-sütunlanmış sepiyolitin alkan serisi adsorpsiyonunun termodinamiği.

\begin{tabular}{cccc}
\hline Adsorbat & $\begin{array}{c}-\Delta \mathrm{H} \\
(\mathrm{kJ} / \mathrm{mol})\end{array}$ & $\begin{array}{c}-\Delta \mathrm{S} \\
(\mathrm{kJ} / \mathrm{molK})\end{array}$ & $\begin{array}{c}-\Delta \mathrm{G} \\
(\mathrm{kJ} / \mathrm{mol})\end{array}$ \\
\hline n-Hekzan & 64,4 & 0,099 & 6,2 \\
n-Heptan & 72,4 & 0,107 & 9,6 \\
n-Oktan & 81,8 & 0,117 & 13,0 \\
n-Nonan & 87,5 & 0,122 & 16,0 \\
\hline
\end{tabular}

Tablo 3. Al-sütunlanmış montmorillonitin alkan serisi adsorpsiyonunun termodinamiği.

\begin{tabular}{cccc}
\hline Adsorbat & $\begin{array}{c}-\Delta \mathrm{H} \\
(\mathrm{kJ} / \mathrm{mol})\end{array}$ & $\begin{array}{c}-\Delta \mathrm{S} \\
(\mathrm{kJ} / \mathrm{molK})\end{array}$ & $\begin{array}{c}-\Delta \mathrm{G} \\
(\mathrm{kJ} / \mathrm{mol})\end{array}$ \\
\hline n-Hekzan & 60,0 & 0,086 & 9,6 \\
n-Heptan & 68,5 & 0,094 & 13,1 \\
n-Oktan & 75,5 & 0,101 & 16,3 \\
n-Nonan & 82,5 & 0,107 & 19,5 \\
\hline
\end{tabular}

Diğer taraftan, incelen maddelerdeki bu üç termodinamiksel parametrenin mutlak değeri alkan zincirindeki karbon sayısı ile doğrusal bir artıș göstermektedir [29]. Kisa zincirli alkanlar uzun zincirlilere göre yüzeye daha güçlü tutunurlar. Alkan zincirindeki karbon sayısının artması adsorpsiyon enerjisinin de artmasına neden olur [30]. Buna ek olarak, Al-sütunlanmış sepiyolitin $-\Delta \mathrm{H}$ ve $-\Delta \mathrm{S}$ değerleri Al-sütunlanmış montmorillonite göre daha yüksektir. Al-sütunlanmış sepiyolitin alkan serisi ile daha kuvvetli bir etkileşiminin olduğu yani ilgisinin daha fazla olduğu söylenebilir.

\section{Tartışma ve Sonuç}

$\mathrm{Bu}$ çalışmada, Al-sütunlanmış sepiyolit ve Alsütunlanmış montmorillonit incelenmiş ve bazı özellikleri karşılaştırılmıştır. Ham sepiyolit ve Alsütunlanmış sepiyolitin FT-IR spektrumlarl, saflaştırma işlemi ile ham sepiyolitte bulunan dolomit safsızlı̆̆ının giderildiğini ve sütunlama işlemi ile Keggin molekülünün eklendiğini göstermektedir. SEM görüntüleri ise Al-sütunlanmış sepiyolitin, lifsi yapısının birleșerek oluşturduğu üst üste yerleşmiş plaka katmanlarını göstermektedir.

Alkanlar kimya endüstrisinin temelini oluşturmaktadırlar. Sayısız kimyasal maddenin üretim aşamasında yardımcı veya hammadde olarak kullanılmaktadırlar. $\mathrm{Bu}$ nedenle alkanların adsorpsiyon özelliklerinin belirlenmesi endüstriyel katıların karakterizasyonu açısından önem teșkil etmektedir. Ters gaz kromatografisi kullanılarak incelenen maddelerin, yüzey serbest enerjisi, alkan serisi için adsorpsiyon entalpisi, adsorpsiyon entropisi ve adsorpsiyon serbest enerjisi hesaplanmıștır. Bu değerler incelenen maddelerin alkanlarla etkileșim kabiliyetlerindeki farklılıkları göstermektedir. Her iki madde için de adsorpsiyon sürecinin ekzotermik olduğu ve kendiliğinden gerçekleştiği (spontane) söylenebilir. Ayrıca Alsütunlanmış sepiyolitin serbest yüzey enerjisi, Alsütunlanmış montmorillonite göre daha düşüktür ve sıcaklıktan daha fazla etkilenmektedir.

$\mathrm{Bu}$ çalışma, ülkemizde hammaddesi yaygın ve ucuz olarak bulunabilen ve katalizör veya adsorban endüstrisinde kullanılabilecek bu iki maddenin şekil, yapı ve yüzey özelliklerinin belirlenmesi ve karşılaştırılması, ayrıca daha önce rapor edilmeyen adsorpsiyon termodinamik verilerinin hesaplanması açısından önem teşkil etmektedir.

\section{Kaynakça}

[1] Lazarević, S., Janković-Častvan, I., Jovanović, D., Milonjić, S., Janaćković, D., Petrović, R. 2007. Adsorption of $\mathrm{Pb}^{2+}, \mathrm{Cd}^{2+}$ and $\mathrm{Sr}^{2+}$ ions onto natural and acid-activated sepiolites. Applied Clay Science, 37, 47-57.

[2] Uz, N. 2013. Stone carving in the locality of eskişehir with its natural and cultural properties: meerschaum. Journal of Arts and Humanities, 2, 140-148.

[3] Işık, İ. 1995. Lületaşı (meerschaum) atıklarının pipo filtresi olarak kullanılabilirliği ve aktif karbon filtre ile karşılaştırılması. Endüstriyel Hammaddeler Sempozyumu, 21-22 Nisan, İzmir, 247-255.

[4] Balci, S., Dinçer, Y. 2002. Ammonium ion adsorption with sepiolite: use of transient uptake method. Chemical Engineering and Processing: Process Intensification, 41, 79-85.

[5] Vicente M. A., Gil A., Bergaya F. 2013. Pillared clays and clay minerals. ss 523-557. Bergaya, F., Lagaly, G. ed. 2013. Development in Clay Science: Handbook of Clay Science, Elsevier, Amsterdam, 813s. 
[6] Figueras, F. 2012. Pillared clays as catalysts. Catalysis Reviews: Science and Engineering, 30, 457-499.

[7] Carriazo, J. G. 2007. Influence of iron removal on the synthesis of pillared clays: a surface study by nitrogen adsorption, XRD and EPR. Applied Clay Science, 67-68, 99-105.

[8] Kloprogge, J. T. 1998. Synthesis of smectites and porous pillared clay catalysts: a review. Journal of Porous Materials, 5, 5-41.

[9] Manohar, D. M., Noeline, B. F., Anirudhan, T. S. 2006. Adsorption performance of Al-pillared bentonite clay for the removal of cobalt(II) from aqueous phase. Applied Clay Science, 31, 194206.

[10] Cordeiro, N., Gouveia, C., Moraes, A. G. O., Amico, S. C. 2010. Natural fibers characterization by inverse gas chromatography. Carbohydrate Polymers, 84, 110-117.

[11] Matsushita, Y., Wada, S., Fukushima, K., Yasuda, S. 2006. Surface characteristics of phenolformaldehyde-lignin resin determined by contact angle measurement and inverse gas chromatography. Industrial Crops and Products, $23,115-121$.

[12] Hole, B. B., Keller, D. S., Burry, W. M., Schwarz, J. A. 2011. Surface energetics of bone mineral and synthetic hydroxyapatite using inverse gas chromatography. Journal of Chromatography B, 879, 1847-1850.

[13] Pérez-Mendoza, M., Almazán-Almazán, C., Méndez-Liñán, L., Domingo-García, M., LópezGarzón, F. J. 2008. Evaluation of the dispersive component of the surface energy of active carbons as determined by inverse gas chromatography at zero surface coverage. Journal of Chromatography A, 1214, 121-127.

[14] Bilgiç, C., Karakehya, N. 2016. Inverse gas chromatographic characterization of polystyrene and organomontmorillonite/polystyrene nanocomposites. Journal of Adhesion Science and Technology, 30, 1945-1956.

[15] Díaz, E., Ordóñez, S., Vega, A., Coca, J. 2004. Adsorption characterisation of different volatile organic compounds over alumina, zeolites and activated carbon using inverse gas chromatography. Journal of Chromatography A, 1049, 139-146.

[16] Lazarević, S., Radovanović, Ž., Veljović, Dj., Onjia, A., Janaćković, Dj. Petrović, R. 2009. Characterization of Sepiolite by Inverse Gas Chromatography at İnfinite and Finite Surface Coverage. Applied Clay Science, 43, 41-48.

[17] Santos, J. M. R. C. A., Guthrie, J. T. 2005. Analysis of interactions in multicomponent polymeric systems: the key-role of inverse gas chromatography. Materials Science and Engineering: R: Reports, 50, 79-107.

[18] Gil, A., Vicente, M. A., Lambert, J. -F., Gandía, L. M. 2001. Platinum catalysts supported on Alpillared clays: application to the catalytic combustion of acetone and methyl-ethyl-ketone. Catalysis Today, 68, 41-51.

[19] Yeniyol, M. 2014. Characterization of two forms of sepiolite and related Mg-rich clay minerals from yenidoğan (Sivrihisar, Turkey). Clay Minerals, 49, 91-108.

[20] Bilgiç, C., Karakehya, N. 2017. Preparatıon and characterization of pillared clays, $15^{\text {th }}$ International Conference on Environmental Science and Technology, 31 August - 2 September, Rhodes, Greece, 5s.

[21] Tabak, A., Eren, E., Afsin, B., Caglar, B. 2009. Determination of Adsorptive properties of a Turkish sepiolite for removal of reactive blue 15 anionic dye from aqueous solutions. Journal of Hazardous Materials, 161, 1087-1094.

[22] Kumararaja, P., Manjaiah, K. M., Datta, S. C., Sarkar, B. 2017. Remediation of metal contaminated soil by aluminium pillared bentonite: synthesis, characterisation, equilibrium study and plant growth experiment. Applied Clay Science, 137, 115-122.

[23] Ongen, A., Ozcan, H. K., Ozbas, E. E., Balkaya, N. 2012. Adsorption of astrazon blue FGRL onto sepiolite from aqueous solutions. Desalination and Water Treatment, 40, 129-136.

[24] Viseras, C., Lopez-Galindo, A. 1999. Pharmaceutical applications of some Spanish clays (sepiolite, palygorskite, bentonite): some preformulation studies. Applied Clay Science, 14, 69-82.

[25] Schmitt, P., Koerper, E., Schultz, J., Papirer, E. 1988. Characterization, by inverse gas chromatography, of the surface properties of calcium carbonate before and after treatment with stearic acid. Chromatographia, 25, 786-790.

[26] Așkın, A., Yazıcı, D. T. 2005. Surface Characterization of Sepiolite by inverse gas chromatography. Chromatographia, 61, 625631.

[27] Bandosz, T. J., Jagiello, J., Amankwah, K. A. G., Schwarz, J. A. 1992. Chemical and structural properties of clay minerals modified by inorganic and organic material. Clay Minerals, $27,435-444$.

[28] Yan, Y., Gao, Y., Tang, W., Li, Q., Zhang, J. 2016. Characterization of high-alumina coal fly ash based silicate material and its adsorption performance to $\mathrm{CO}_{2}$. Korean Journal of Chemical Engineering, 33, 1369-1379. 
[29] Bilgiç, C., Tümsek, F. 2007. Determination of the acid/base properties of $\mathrm{MgY}$ and $\mathrm{NH}_{4} \mathrm{Y}$ molecular sieves by inverse gas chromatography. Journal of Chromatography A, 1162, 83-89.
[30] Wetterer, S. M., Lavrich, D. J., Cummings, T., Bernasek, S. L. , Scoles, G. 1998. Energetics and Kinetics of the Physisorption of Hydrocarbons on $\mathrm{Au}(111)$. The Journal of Physical Chemistry B, 102, 9266-9275. 